\title{
The Impact of the "The Belt and Road" Strategy on China and Countries along the Route
}

\author{
Sirui $\mathrm{Li}^{* 1}$ \\ ${ }^{1}$ Jiyang College of Zhejiang Agriculture and Forestry University, Zhuji, Zhejiang 311800,China \\ *Corresponding author's Email: 1339934805@qq.com
}

\begin{abstract}
This article analyzes the impact of the "The Belt and Road" strategy on our country through the "The Belt and Road" strategy's promotion of the renewal and development of domestic enterprises in China, trade frictions, RMB internationalization, and the spread of traditional Chinese culture. It also discusses the impact of the "The Belt and Road" strategy on the countries along the route from multiple perspectives of OFDI, infrastructure construction and energy development. On the basis of in-depth research, to promote the future development of the "The Belt and Road" strategy, attention should be paid to the need to continue to promote existing policies and projects, expand the number of participating countries and increase influence, and improve the strategic plans related to the tertiary industry.
\end{abstract}

Keywords: 'The Belt and Road', Trade.

\section{INTRODUCTION}

With the introduction and advancement of our country's "The Belt and Road" cooperation initiative, the development of our country's import and export trade has entered a new stage. As a regional cooperation platform to promote exchanges and cooperation between countries and expand the scale of bilateral import and export trade, "The Belt and Road" fully integrates the economic development of China and the countries along the route. Through China's driving and promotion, the enthusiasm of countries along the route will be increased, and a new cooperation mechanism that meets the requirements of the new era will be created. As of November 2020, China has signed 201 cooperation documents for jointly building the "The Belt and Road" with 138 countries and 31 international organizations.

"The Belt and Road" is the abbreviation of "The Silk Road Economic Belt" and "21st-Century Maritime Silk Road". These two cooperation initiatives were initiated by Chinese President $\mathrm{Xi}$ Jinping when he visited Kazakhstan in September 2013 and when he visited ASEAN countries in October put forward. The B\&R inherited and developed the ancient "Silk Road". The ancient "Silk Road" has a long history and can be traced back to the Qin and Han dynasties. The route of silk on land was opened by the outstanding diplomat of the Western Han Dynasty by Zhang Qian, the capital of
Chang'an (now Xi'an). As the starting point and ending with Rome, the Maritime Silk Road starts from the southeastern coast of China and reaches as far as the east coast of Africa. Based on the role of the ancient "Silk Road" linking the political, economic and cultural exchanges between China and the West, the B\&R strategy expanded the route range, increased the number of countries along the route, and sublimated the purpose of trade with countries along the route.

Han Yonghui and Zou Jianhua (2014) believe that with the expansion of the scale of bilateral imports and exports and the strengthening of trade exchanges, the $\mathrm{B} \& \mathrm{R}$ will become a powerful starting point for the construction of China's all-round open pattern, and will ensure the fundamental interests of people in China and Western Asia. On the basis of this, exchange what is needed and promote peace and development. Shen Xianjie and Xiao Jincheng (2014) believe that in the face of the slow progress of multilateral mechanisms and the increasingly high standard and comprehensiveness of regional trade agreements, China's implementation of the B\&R strategy can not only give full play to its role in international regional cooperation. The positive effect can also effectively cope with the external pressure caused by the US-led TPP and TTIP on China. Dong Hong and Lin Huihui (2015) believe that the B\&R strategy has opened a new stage in our country's foreign trade policy, transportation, and finance. Faced with the constraints 
of trade frictions, Chinese foreign trade companies should take preventive measures to deal with them. Li Fengliang and Yuwen Manqian (2016) believe that the development of cultural industries is one of the important entry points of the "Belt and Road" strategy. At the same time, the "Belt and Road" strategy also provides an opportunity for the upgrading of our country's cultural industry structure and promotes Chinese culture to "go global". Wang Yuxin and Jian Xiang (2018) believe that the "Belt and Road" is currently our country's main strategy to meet the requirements of globalization and promote international regional economic cooperation and development. In the process of trade between China and the countries along the "Belt and Road", the original The political and diplomatic relations of China have been consolidated, and free trade agreements have been promoted.

In recent years, China and the countries along the B\&R have increasingly frequent import and export trade exchanges. This strategy aims to emphasize common construction and common development, rather than the strategic purpose of focusing on China's interests. In the process of advancing the development of the $B \& R$ strategy, China's trade exchanges with countries along the route have great room for development and opportunities, which will have a certain impact on the import and export trade of our country and the countries along the route. Development trends and effects are of great significance.

\section{THE IMPACT OF "THE BELT AND ROAD” ON CHINA}

\subsection{Promote the renewal and development of local enterprises}

While the $\mathrm{B} \& \mathrm{R}$ strategy promotes trade between China and countries along the route, it also brings tremendous external pressure to Chinese export companies. Faced with the different import policies and technical regulations implemented by importing countries, on the one hand, Chinese exporting companies have suffered huge export pressure; on the other hand, the strict technical regulations and import standards of importing countries have promoted the development of Chinese exporting companies to a certain extent. Update development. Chinese export companies are no longer blindly seeking to reduce the cost of exported products, but insist on the transformation and upgrading of their corporate structure, and shift their development direction to highprecision technology. For labor-intensive industries, it can also be achieved by improving production technology. Reduction of production costs.

Due to the upgrading and transformation of export enterprises, the market's demand for high-tech talents continues to expand. The $\mathrm{B} \& \mathrm{R}$ strategy provides a platform for talent exchanges between countries Countries have conducted in-depth cooperation and exchanges in science and technology, education, etc. And even jointly built a talent development and education base for the two countries on the basis of friendship and mutual benefit. The increasing number of outstanding domestic talents has become a major boost to the development of the country's export trade, providing assistance to local enterprises in terms of production technology, and providing a guarantee for weakening the pressure of external competition.

\subsection{Trade friction}

In the face of the prevailing background of trade protectionism, as well as the ambiguity of WTO provisions and the inadequacy of dispute mechanisms, some problems have also arisen in the course of trade between China and the countries along the B\&R strategy, such as the inconsistency of trade between the two countries, dumping and anti-dumping issues, issues related to trade in textile products and agricultural products, etc. The difficulty of resolving trade issues has led to constant trade frictions, and the scope of their fields is also expanding. The trade frictions brought about by the "The Belt and Road" are in various forms. The common ones include technical trade barriers, green trade barriers, health and quarantine standards, etc. In addition to tangible trade in goods, it also involves intangible trade in services. According to statistics from the China Trade Remedy Network, from 2010 to 2020, among the global trade remedy cases initiated against China, there were 717 anti-dumping cases, accounting for $67.39 \%, 152$ countervailing cases, accounting for $14.29 \%$, and 192 safeguard measures, accounting for $18.05 . \%$, there were 3 special safeguard measures, accounting for $0.28 \%$. In the trade investigations on Chinese products, the main forms are anti-dumping and countervailing, and the products involved are mainly steel products, textiles, chemicals, food and other products.

Under the "The Belt and Road" strategy, facing the huge demand market of developing countries along the route, the rapid development of our country's foreign trade has also brought more hidden dangers of trade frictions. To a certain extent, the continuous occurrence of trade friction incidents can effectively alert Chinese export companies and increase their awareness of trade friction prevention, prompting Chinese export companies to improve their product core competitiveness and the degree of corporate internationalization, while greatly reducing our country's foreign trade. The frequency of investigations into trade remedy cases. 


\subsection{RMB Internationalization}

Currency internationalization means that a country's currency is accepted by countries or individuals or institutions outside the country where the currency is issued, and the main functions of the currency are performed on an international scale. As RMB internationalization can help China maintain the value of foreign exchange reserves, promote cross-border transactions, and reduce exchange rate risks faced by Chinese companies, China has been actively participating in the establishment of regional financial structures to promote RMB internationalization. In recent years, China has successively signed bilateral local currency settlement agreements with 9 neighboring countries including Vietnam, Laos, and Kazakhstan, as well as countries along the "The Belt and Road", and with 23 neighboring countries such as Russia, Indonesia, and Turkey, and countries along the "The Belt and Road".[1] Signed a bilateral domestic currency swap agreement. The bilateral monetary and financial cooperation between China and the countries along the "The Belt and Road" has been continuously strengthened, but the process of RMB internationalization still faces many obstacles. In the international bulk commodity market, pricing models such as "gold, oil-U.S. dollars" are usually adopted. Since this pricing model cannot be broken in the short term, this will lead to the lack of support for the internationalization of the RMB in the use of local currencies in countries along the "The Belt and Road".[2] In addition, although China has become the world's second largest economy, China's current economic strength still needs to be strengthened, the existing economic system needs to be further improved, and the problems in the economic environment need to be resolved.

The B\&R strategy provides a platform for the internationalization of the RMB. With the strengthening of trade exchanges and capital flows between China and countries along the route, it has promoted cooperation with export credit agencies of countries related to the "The Belt and Road" initiative, and RMB cross-border investment has also expanded. Relying on trade renminbi settlement and exporting renminbi capital abroad, promote the expansion of renminbi circulation in neighboring countries or regions, increase renminbi reliance and demand, gradually develop from peripheralization to regionalization, and finally complete the internationalization of RMB.

\subsection{The spread of Chinese traditional culture}

As an important part of a country's comprehensive national strength, cultural soft power has a prominent role that cannot be ignored in exchanges and cooperation between countries. While promoting our country's economic development, the "The Belt and Road" strategy has also become an important way for Chinese culture to go abroad and face the world, driving Chinese culture to "go global." Dating back to the ancient "Silk Road", the ancient Chinese culture relied on it to link Persian culture, Indian culture, Arab culture, ancient Roman culture and ancient Greek culture, and promoted the exchange and development of the material culture and spiritual culture of the East and the West. In the face of cultural competition in other Asian countries with similar cultural backgrounds and obstacles encountered in the process of cultural exchanges in our country, the "The Belt and Road" strategy has inherited the excellent spirit of the ancient "Silk Road" and persisted in promoting the spread of "Harmony Culture" , To strengthen cooperation between cultural institutions of various countries, adhere to the inclusiveness, mutual respect, and seek common ground while reserving differences between different cultures, extensively carry out cultural and academic exchanges with countries along the route, and promote a new model of mutual promotion and cooperation between countries, regions and nations along the "The Belt and Road" And the formation of a new pattern.

Of course, the "The Belt and Road" strategy brings not only opportunities but also challenges to the spread of Chinese culture.[3] The countries along the "The Belt and Road" not only involve countries with similar cultural backgrounds, but also countries with obvious differences in cultural customs. Facing different countries along the route, we need to adopt different methods for friendly exchanges and focus on how to help build a community with a shared future for mankind. And strengthen cultural dissemination, rationally plan the dissemination mechanism, achieve pioneering and innovative, and prudent promotion.

\section{THE IMPACT OF "THE BELT AND ROAD” ON COUNTRIES ALONG THE ROUTE}

\subsection{OFDI}

With the increasing frequency of trade exchanges between our country and the countries along the "The Belt and Road" , China's foreign direct investment and foreign direct investment attracted by our country are interdependent. [4] This two-way investment method has caused certain influences for our country and the countries along the "The Belt and Road". The development of China's economy has prompted continuous growth in the scale of China's foreign direct investment (OFDI). Our country's outward direct investment in countries along the "The Belt and Road" usually adopts two methods: new construction and acquisition. That means, through direct capital export, the establishment of a new country in the host country 
The enterprise may acquire an existing enterprise in accordance with the relevant laws and regulations of the host country. For example, Alibaba continuously invests in e-commerce company Lazada, controls $83 \%$ of its equity, and guided Lazada to acquire Redmart, a Singapore e-commerce company, to expand its business to other areas. Countries along the B\&R are an important area of OFDI. The scale of China's outward direct investment in Southeast Asia and South Asia is larger than that of Europe. However, because the scale of investment flowing to developed countries has more Expansion capacity, China's direct investment in developed countries has also grown faster.[5]

At the same time, the "The Belt and Road" strategy has provided countries along the route with the convenience of direct investment in China, and OFDI has also shown a new development trend. As one of the most attractive investment destinations for foreign investment, our country's foreign investment inflows have shown a steady growth trend. . According to statistics from the National Bureau of Statistics, our country's total imports and exports to countries along the "Belt and Road" in 2019 totaled 926.9 billion yuan, an increase of $10.8 \%$ over the previous year. Among them, exports were 5,258.5 billion yuan, an increase of $13.2 \%$; imports were $4,010.5$ billion yuan, an increase of $7.9 \%$.

\subsection{Infrastructure}

Due to the large number of countries participating in the "The Belt and Road" strategy, there are great differences among countries, and there are obvious imbalances in the infrastructure layout of countries and regions along the route. The improvement of infrastructure will also become a guarantee for exchanges and cooperation between China and other countries along the route. Therefore, infrastructure construction will become a key industry for China's direct investment in countries and regions along the "The Belt and Road".[6]

In terms of transportation, China has developed close cooperation with countries along the "The Belt and Road", investing a large amount of capital and technical personnel to help countries and regions with weak transportation infrastructure complete the construction.[7] For example, the construction of the "The Belt and Road"and the construction of the JakartaBandung high-speed railway, a landmark project of practical cooperation between China and Indonesia, connects Jakarta, the capital of Indonesia, and Bandung, the fourth largest city, effectively shortening travel time and promoting local development. Economic development has facilitated people's travel. In addition, the improvement of transportation infrastructure has also promoted the development of the logistics industry to a certain extent. As an industry with rapid economic development, e-commerce cannot do without the support of logistics services, and the transportation of goods in the logistics industry is also inseparable from the perfection of the transportation infrastructure.[8] As Shaquille Lamai, Director of the China Research Center of the Pakistan Institute for Sustainable Development Policy, said: "China's investment in the transportation sector will undoubtedly help the development of global logistics, supply chains and transportation networks, and make global logistics and supply chains more efficient. Reliable, every country can benefit from it."

In terms of power investment, China has carried out power investment projects in Pakistan, Laos, Ethiopia and other countries along the route, such as the Karot Hydropower Station, the Segon Transmission and Transformation Project, and the Xiakaifu Gorge Hydropower Station. The increase in power investment projects has promoted the increase in the export of power equipment in our country, and has also brought more advanced power technology to the countries along the route, which can help countries along the route pay attention to the training of power technology talents and provide guarantees for economic development.[9]

\subsection{Energy}

Among the countries along the "The Belt and Road", some countries have abundant energy resources, and energy is an important competitiveness, but in other countries, it may be a shortcoming in development. Energy-rich countries such as Central Asian countries have abundant energy reserves, but due to the backward infrastructure system, energy output is restricted and hindered, and the unique resource advantages cannot be transformed into economic advantages. For another example, some Southeast Asian countries have huge potential for renewable resources, but they are generally plagued by power shortages.

The "The Belt and Road" strategy has brought a new pattern of energy cooperation between China and countries along the route. On the basis of promoting the formation and development of the global energy Internet, a series of service centers have been formed around the development, processing and transportation of energy to provide convenience in production or consumption for countries along the route.[10]

\section{SUGGESTIONS FOR THE FUTURE DEVELOPMENT OF "THE BELT AND ROAD"}

\subsection{Continue to promote existing policies and projects}

The "The Belt and Road" strategy is a medium and long-term leadership strategy for our country. We need to look at every policy and every step of the strategy 
with a long-term perspective to ensure its overall and win-win.[11] The "The Belt and Road" strategy has injected new growth momentum into the world economy and brought opportunities for the current growth difficulties encountered by countries along the route. In the development and advancement in recent years, the areas covered by the "The Belt and Road" strategy have gradually expanded, and corresponding policies have emerged to provide corresponding guarantees for China's trade with countries along the route. At present, the "The Belt and Road" is in the implementation stage of steady development. In the later development, we should make full use of the existing bilateral and multilateral mechanisms to continue to promote the implementation of existing policies and the development of projects, and actively build and follow the route. The flexible and open strategic partnership network between countries allows our country and the countries along the route to enjoy the convenience and dividends brought about by the "The Belt and Road" strategy.

\subsection{Expand the number of countries participating in the strategy}

Faced with the constantly changing international situation, under the background of the "The Belt and Road" strategy, the government's primary task is to actively establish stable and reliable diplomatic relations with countries along the route to provide important guarantees for international trade. In addition, on the basis of friendly diplomacy, preferential policies and strengthening the protection of intellectual property rights should be adopted to attract more interested countries to participate in the strategy. The increase in the number of participating countries reflects the correctness and guidance of the "The Belt and Road" strategy to a certain extent, and can also effectively enhance our country's participation and influence in the international trade market. However, as the number of strategic participating countries increases, some trade problems will arise due to the different market access principles of countries along the route in international trade. In the face of these problems, the Chinese government should actively promote the establishment of the "The Belt and Road" international trade information network, timely update the market access principles of different countries along the route and the market information of the countries along the route, and provide information support for Chinese enterprises.

\subsection{Improve the strategic plan for the tertiary industry}

In recent years, the tertiary industry in China's industrial structure has developed rapidly, and its proportion has risen to become our country's largest industry. Looking at the overall situation, the current
"The Belt and Road" strategy still lacks in the layout of the tertiary industry. Although the areas involved are expanding, the relevant systems and systems are still not perfect, and the industrial planning lacks depth. Taking the sports industry as an example, the overcapacity in the sports industry sector and the insufficient supply of the sports service sector have hindered the transformation of the sports industry from the secondary industry to the tertiary industry. In this regard, our country should continue to strengthen the investment and construction of sports infrastructure, and the transfer of the sports goods manufacturing industry to promote the upgrading and development of the sports industry. In the future development of the "The Belt and Road" strategy, attention should be paid to the improvement and implementation of the tertiary industry strategic plan, aiming at areas with high demand and sufficient development space, and continuously promoting the development and upgrading of various industries. At the same time, we must adhere to the concept of openness, greenness, and integrity, and use green as the background color to promote green infrastructure construction, green investment, and green finance, and strive to achieve high standards and sustainable goals.

\section{CONCLUSION}

The "The Belt and Road" strategy is composed of the "The Silk Road Economic Belt" and "21st-Century Maritime Silk Road". It is a long-term strategy of profound significance in our country. This article deeply researches and analyzes the impact of the strategy on our country and countries along the route from multiple angles, and puts forward several suggestions that can be implemented in future strategic planning. Regarding the influence of China, the "The Belt and Road" strategy has promoted the renewal and development of Chinese local enterprises to a certain extent. While enterprises rely on upgrading and transformation to face external pressures, they have also promoted the exchange of talents. Secondly, with the strengthening of trade exchanges, trade frictions continue to occur, and trade problems such as anti-dumping and anti-subsidy still find effective solutions. However, the "The Belt and Road" initiative has also promoted the internationalization of the renminbi, relying on crossborder investment and other channels to increase the dependence and demand on the renminbi, thereby achieving internationalization. In addition, the "Belt and Road" has been a platform for the dissemination of Chinese traditional culture since ancient times, promoting Chinese culture to "go global." The impact on the countries along the route, on the one hand, has facilitated the two-way investment between China and the countries along the route, and strengthened the exchange of funds between countries. On the other hand, it will give a big boost to the countries along the 
route with weak infrastructure and help them to continuously improve their infrastructure construction, thereby promoting domestic and foreign exchanges and cooperation among the countries along the route. In addition, the "The Belt and Road" initiative also provides a way for countries along the route that are rich in energy resources but cause unnecessary accumulation and consumption due to technology and other reasons. Regarding suggestions for the future development of the "The Belt and Road", the first is to make full use of existing bilateral and multilateral mechanisms to continue to promote existing policies and projects; the second is to enhance strategic influence and expand the number of participating countries; the third is to find areas where the current strategy is still to be developed, and to improve the relevant strategic plans for the tertiary industry.

\section{REFERENCES}

[1] Gao Haihong, Yu Yongding. The meaning and conditions of RMB internationalization[J]. International Economic Review, 2010(01):43-61.

[2] Li Daokui, Liu Linlin. RMB Internationalization: Quantitative Research and Policy Analysis[J]. Financial Research, 2008(11):1-16.

[3] Cao Aijun, Chen Si. Research on Chinese Culture "Going Global" under the Background of "The Belt and Road" [J]. Journal of Shijiazhuang University of Economics, 2016(6): 112-118, 7 pages.

[4] Lan Qingxin, Liu Zhaojie. The influence of the "The Belt and Road" strategy on my country's attraction of foreign investment and promotion measures[J]. Qinghai Social Sciences, 2017(2).

[5] Liu Laihui. China's direct investment in countries along the "The Belt and Road": Status Quo, Motivation and Policy RecommendationsBased on Heckman's Two-Phase Empirical Research [J]. International Business (Journal of University of International Business and Economics), 2017(05) ): 44-54.

[6] Zhang Hanlin. "The Belt and Road" Initiative Infrastructure Construction International Financial Cooperation System Research [J]. Theoretical Discussion, No.201(02):91-98.

[7] Xu Jiao, Chen Kunming, Yang Shufei, et al. The international economic and trade effects of the "Belt and Road" transportation infrastructure construction[J]. Asia-Pacific Economics, 2016(3): 3-11.

[8] Ouyang Minghui. Discussion on strengthening the modern logistics service system and its infrastructure under the "The Belt and Road" initiative $[\mathrm{J}]$. Business Economics Research, 2017(24): 80-82.

[9] Cheng Jian, Fu Fangchao. Suggestions for the power industry to "go global" under the "The Belt and Road" strategy[J]. Cooperative Economy and Technology, 2016(13): 18-19.

[10] Liu Jiajun. The new pattern of China's energy cooperation under the background of the "The Belt and Road" strategy[J]. International Economic Cooperation, 2015, 000(010): 30-33.

[11] Zhang Monan. Comprehensively enhance the development level of the "The Belt and Road" strategy [J]. Macroeconomic Management, 2015, 000(002): 20-24. 